\title{
Retrograde Transport of Radiolabeled Cytoskeletal Proteins in Transected Nerves
}

\author{
Jonathan D. Glass ${ }^{1,2}$ and John W. Griffin ${ }^{1.3}$ \\ Departments of ${ }^{1}$ Neurology, ${ }^{2}$ Pathology (Neuropathology), and ${ }^{3}$ Neuroscience, The Johns Hopkins University School of \\ Medicine, Baltimore, Maryland 21287
}

\begin{abstract}
Slow axonal transport is the mechanism by which cytoskeletal proteins are distributed within the axon. This function has traditionally been considered an exclusively unidirectional, anterograde process. Previous observations of cytoskeletal redistribution in surviving, transected axons of the C57BL/Ola mouse led us to hypothesize a retrograde component of cytoskeletal transport. To test this hypothesis against previous methods of measuring slow transport of cytoskeleton, we radioactively pulse-labeled proteins in sensory neurons of C57BL/Ola mice and followed their redistribution by gel fluorography in ligated and unligated sciatic nerves. Slow axonal transport of cytoskeletal proteins proceeded with the same characteristics in C57BL/Ola as in standard C57BL/6 mice. In comparison to the transport profiles from unligated control nerves, in ligated nerves there was redistribution of radiolabeled neurofilament and tubulin proteins back toward the cell body during the $14 \mathrm{~d}$ experimental period. These observations demonstrate that pulselabeled cytoskeletal proteins move bidirectionally in this experimental system, and may provide insight into the normal mechanisms of cytoskeletal maintenance.
\end{abstract}

[Key words: axonal transport, neurofilament, tubulin, cytoskeleton, Ola mouse, axotomy]

The movement of proteins between the cell body, axon, and nerve terminal by axonal transport has been delineated by following the redistribution over time of pulse-labeled proteins in nerve. This strategy has identified different classes of transport based on the rates and the major proteins carried within these classes (for review, see Vallee and Bloom, 1991). The two major components of axonal transport, fast and slow transport, carry membrane-bound and cytoskeletal proteins, respectively. Fast axonal transport is composed of both anterograde and retrograde components that carry polypeptides from and to the cell body at rates of $100-400 \mathrm{~mm} / \mathrm{d}$. Retrograde fast transport was originally identified and characterized by two methods: (1) labeled molecules were injected near the nerve terminals and later identified within the corresponding cell bodies (Kristensson and Sjostrand, 1972; LaVail and LaVail, 1974; Price et al., 1975),

\footnotetext{
Received Sept. 2, 1993; revised Dec. 14, 1993; accepted Dec. 31, 1993.

We thank David Figueroa, Brenda Schryer, and Ken Fittro for technical assistance, Paul Hoffman and Pamela Talalay for helpful discussion, and Rod Graham for manuscript preparation. This work was supported by Grants RO1-14784, NS01577, and PO1-22849 from the National Institute of Neurological Diseases and Stroke.

Correspondence should be addressed to Dr. Jonathan Glass, Pathology 616, Department of Neurology, 600 North Wolfe Street, Baltimore, MD 21287-6965.

Copyright (C) 1994 Society for Neuroscience 0270-6474/94/143915-07\$05.00/0
}

and (2) nerves were ligated or cooled and the accumulation of markers was demonstrated just distal to the ligation (Zelena et al., 1968; Bisby, 1976; Griffin et al., 1976; Brimijoin and Wiermaa, 1977; Griffin et al., 1977). Neither of these approaches has been useful for investigating the possibility of a retrograde component of slow transport. First, the exogenous markers that have been injected into nerve or at nerve terminals are typically soluble proteins that are taken up into vesicles and carried by the fast transport system, and none have moved slowly toward the cell body. Two exceptions may be labeled serum albumin (Gainer and Fink, 1982), and radiolabeled lead (Baruah et al., 1981). Second, ligation protocols to study the redistribution of endogenous slow component proteins have not been feasible because the relatively brief period (1-3 d) during which the mammalian axon survives after transection is too short to resolve the movement of slow component markers that move only $0.1-4 \mathrm{~mm} / \mathrm{d}$. Slow axonal transport is thus usually considered to consist of only an anterograde component.

Our recent morphologic and immunochemical observations showing redistribution of cytoskeletal constituents in transected nerves of the C57BL/Ola mouse (Ola) led us to propose a retrograde component of slow transport in these transected axons (Glass and Griffin, 1991; Watson et al., 1993). The Ola mouse is a mutant substrain in which transected axons do not degenerate for up to 4 weeks after axotomy (Lunn et al., 1989; Glass and Griffin, 1991). This mouse provides a unique system in which to test hypotheses regarding retrograde slow transport by mcthods similar to those used previously for fast transport. We have already shown that cytoskeletal constituents are gradually redistributed bidirectionally in the distal stump during 1-3 weeks after transection. Morphologically this redistribution is manifested as accumulations of neurofilaments in the most proximal and distal extents of transected axons (Glass and Griffin, 1991). Analysis for specific cytoskeletal proteins by ELISA showed similar patterns of redistribution and accumulation for both neurofilaments and tubulin (Watson et al., 1993). In order to test whether this observed redistribution of cytoskeletal proteins represents axonal transport as previously defined by pulse-labeling methods, we radiolabeled newly synthesized cytoskeletal proteins in sensory neurons of the Ola mouse and examined the redistribution of label in intact and axotomized sciatic nerves.

\section{Materials and Methods}

C57BL/Ola mice were obtained from a breeding colony maintained at the Johns Hopkins Medical Institutions. All surgical procedures were done on 30-d-old male and female animals under methoxyflurane inhalation anesthesia. After surgery, animals were housed in an AAALACaccredited facility and allowed access to food and water ad libitum. All 


\begin{tabular}{|c|c|c|c|}
\hline & Group 28/42 & Group 35/49 & Group 56/70 \\
\hline \multirow[t]{2}{*}{ Test animal } & Ligate day 28 & Ligate day 35 & Ligate day 56 \\
\hline & Death day 42 & Death day 49 & Death day 70 \\
\hline Control & Death day 28 & Death day 35 & Death day 56 \\
\hline Control & Death day 42 & Death day 49 & Death day 70 \\
\hline
\end{tabular}

procedures were approved by the Animal Care Committee of the Johns Hopkins Medical Institutions.

Labeling procedure. Anesthetized animals underwent a left L4 and L5 lateral laminectomy to uncover the L5 dorsal root ganglion (DRG). The animal was suspended via toothed tissue forceps fixed snugly around vertebral bodies above and below the laminectomy site and attached to magnetic flexbar holders. This procedure prevented the animal's breathing movements from interfering with the injection procedures. Two microliters of ${ }^{35} \mathrm{~S}$-methionine ( $100 \mu \mathrm{Ci} / \mu \mathrm{l}$; New England Nuclear) were injected over $\sim 15 \mathrm{~min}$ using a glass micropipette mounted on a micromanipulator and driven by a Harvard syringe pump. After injection, the animals were returned to their cages until the next surgical procedure or death. Comparison experiments (see below) were done by injecting at least three litter mates at one sitting, to minimize interanimal variation.

A single experimental set consisted of three injected animals (Table 1). One animal in each set was killed at 28,35 , or $56 \mathrm{~d}$ after injection (see below). At the same time, a second animal underwent ligation of the labeled sciatic nerve approximately $8 \mathrm{~mm}$ from the L5 DRG, and just distal to the takeoff of the gluteal nerve. This was done by separation of the sacroiliac joint with pointed scissors and ligation with 6-0 silk suture. To assure complete axonal transection, the nerve was then crushed with \#5 Dumont forceps just proximal to the suture. The third animal in each set was left undisturbed. Fourteen days later (i.e., 42, 49, $70 \mathrm{~d}$ after labeling), the ligated and undisturbed animals were anesthetized and killed by cardiac transection. Labeled nerves were harvested by dissecting the DRG and sciatic nerve in continuity to the level of the knee. These preparations were extended to their full lengths on a plastic ruler, frozen on dry ice, and stored at $-70^{\circ} \mathrm{C}$ until the time of analysis.

Under a dissecting microscope, the nerves were cut into $2 \mathrm{~mm}$ segments beginning at the DRG and proceeding distally. Each $2 \mathrm{~mm}$ segment was homogenized in a glass-on-glass homogenizer (Micrometrics Instruments, Tampa, FL) containing $100 \mu \mathrm{l}$ of urea gel sample buffer (6 $\mathrm{m}$ urea, $2 \%$ SDS, $10 \%$ glycerol, $0.1 \%$ bromphenol blue, $10 \% \beta$-mercaptoethanol, in $0.5 \mathrm{~m}$ Tris buffer $\mathrm{pH} 6.8$ ). Samples were boiled and centrifuged and $5 \mu \mathrm{l}$ aliquots were counted for ${ }^{35} \mathrm{~S}$-methionine activity by liquid scintillation spectroscopy. The remainder of the sample was loaded onto a single lane of a vertical slab polyacrylamide gel (7.5\%) and electrophoresed at constant current. Gels were fixed in $50 \%$ methanol, $10 \%$ glacial acetic acid, soaked for $3 \mathrm{hr}$ in 2,5-diphenyloxazole/ dimethyl sulfoxide, and dried under vacuum and heat onto filter paper. Dried gels were exposed to $\mathrm{x}$-ray film for periods of $4 \mathrm{~d}$ to 4 weeks to produce gel fluorograms.

Quantitation of labeled proteins. The bands corresponding to the neurofilament and tubulin proteins, as identified by their corresponding molecular weights, were analyzed for their relative densities on the x-ray film with a Molecular Dynamics laser densitometer that quantitates

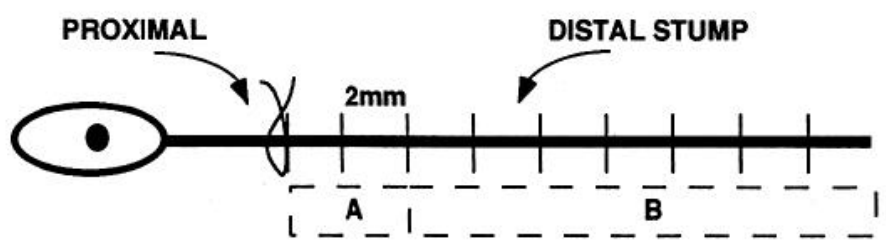

Figure 1. Schematic representation of sampling strategies for quantitative analysis of axonal transport in the distal stump. The proportion of labeled proteins in the first two segments $(A)$ was compared to that in the remainder of the stump $(B)$. These data were compared to those in the corresponding segments of the unligated control nerves.

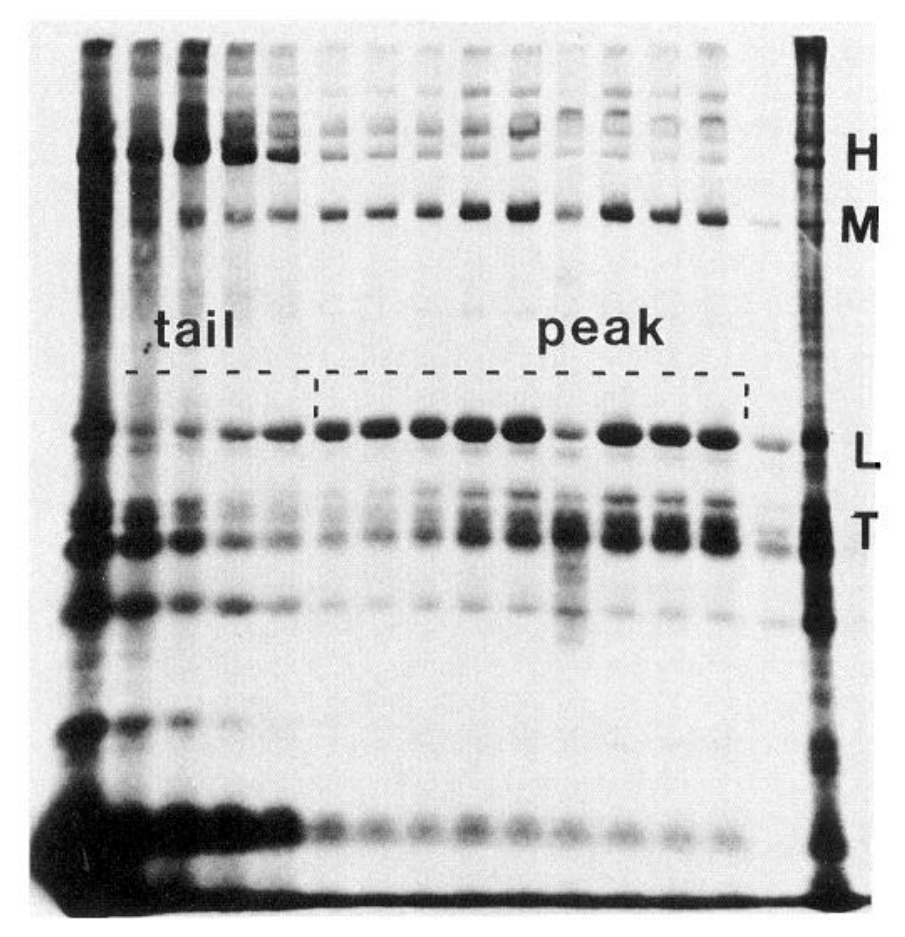

Figure 2. Gel fluorogram from the sciatic nerve of a standard C57BL/6 mouse harvested $36 \mathrm{~d}$ after injection of radiolabel in the L5 DRG. Each lane represents the homogenate of a $2 \mathrm{~mm}$ segment of nerve taken sequentially (left to right) from the DRG distally. The last lane is from a special preparation of nerve that isolates insoluble cytoskeletal constituents, and is used as a marker for the neurofilament bands $(H, M$, and $L$ ) and tubulin bands $(T)$. Note that the transport profiles for neurofilament and tubulin show up as broad peaks which span many segments with significant "tails" of radioactivity that are retained in more proximal segments. The peak and tail are labeled for the neurofilament- $\mathrm{L}$ band.

gray-scale pixel values $(0.0-4.095 \mathrm{OD})$ within the entire volume of the band. The bands corresponding to the 68,160 , and $200 \mathrm{kDa}$ epitopes of neurofilament, and the 53 and $57 \mathrm{kDa}$ epitopes of tubulin were outlined on the digitized computer-screen image, and the volume data for each band was transferred to a spreadsheet program (Microsoft EXCEL).

Analysis of transport. The distribution of labeled neurofilament and tubulin proteins was assessed by visual inspection of the gel fluorograms, and by quantitative analysis with laser densitometry. The percentage of labeled protein in each nerve segment for each of the neurofilament and tubulin epitopes was calculated by dividing the densitometric volume in each segment by the sum of volumes for that epitope within the whole nerve. The data for the subunits of each protein were also combined to give percentages for total labeled neurofilament and tubulin. In order to focus attention on cytoskeletal redistribution in the transected distal stumps, the same type of analysis was done after excluding the data from the region proximal to the ligation, and comparing the distal segments to the corresponding segments in the unligated control nerves. In addition, the percentage of labeled proteins in the segments just distal to the ligation (or in the corresponding segments in the unligated nerves) was alsc compared to that in the remainder of the nerve (Fig. 1). Comparing ligated and unligated nerves in this way identified shifts in the regional distribution of the labeled cytoskeletal proteins that reflect the axonal transport of these proteins.

\section{Results}

A total of 75 mice were injected and killed at time points between 7 and $70 \mathrm{~d}$. We first asked if the rate and characteristics of slow axonal transport were the same in standard C57 and in Ola mice. The transport profiles at several time points between 14 and $36 \mathrm{~d}$ after labeling were similar in these two strains, with 

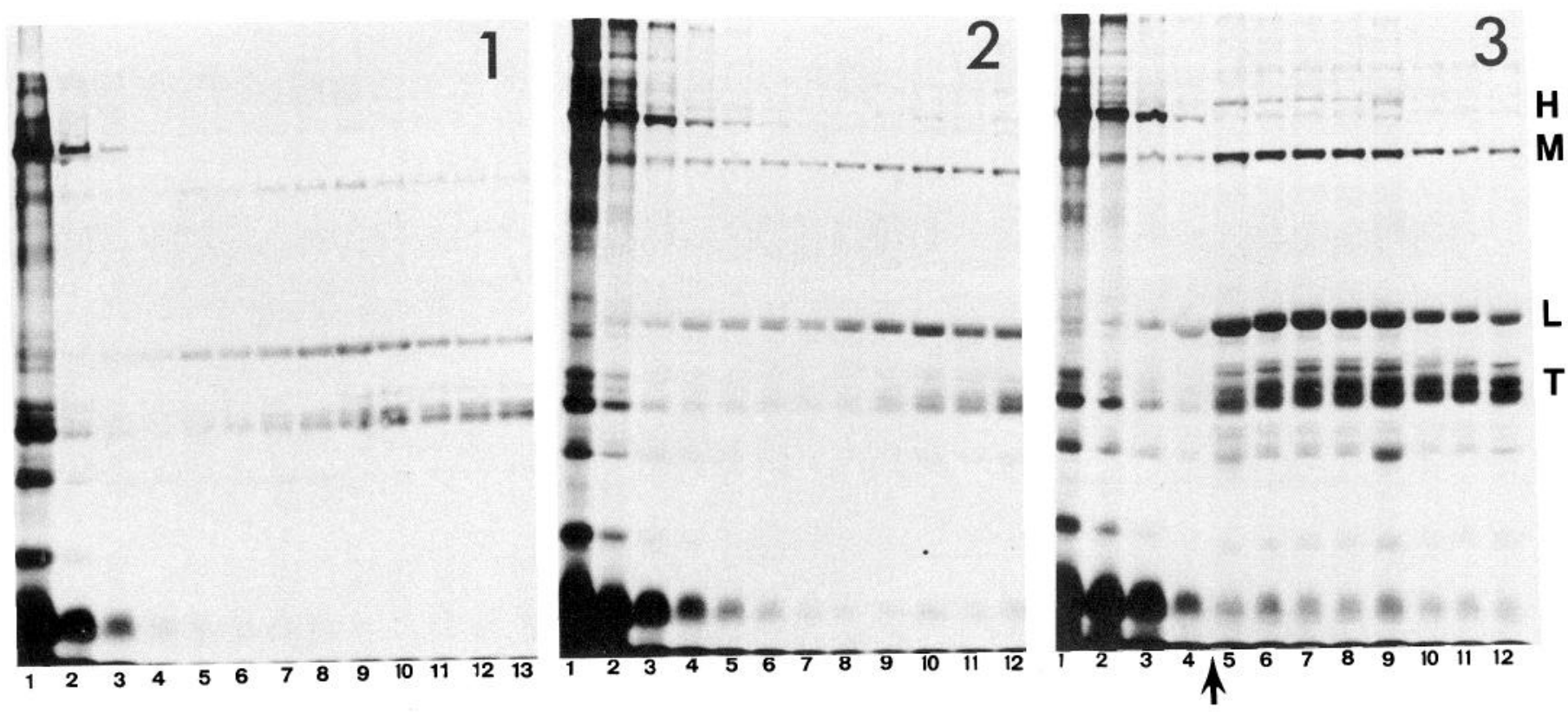

Figure 3. Gel fluorograms from the representative animals 1-3 from set 35/49. Each lane represents the homogenate of a $2 \mathrm{~mm}$ segment of nerve taken sequentially from the DRG distally. Animal 1 was killed at $35 \mathrm{~d}$ after labeling; animal 2 was killed $49 \mathrm{~d}$ after labeling; in animal 3 the sciatic nerve was ligated between segments 4 and 5 (arrow) at $35 \mathrm{~d}$, and the animal was killed at $49 \mathrm{~d}$ after labeling. Note in the fluorograms from animals 1 and 2 the distal progression of the labeled bands between 35 and $49 \mathrm{~d}$. In the fluorogram from animal 3 there is an accumulation of labeled proteins just distal to the ligation; the majority of labeled neurofilament and tubulin proteins are found in segments more proximal to the DRG than at $35 \mathrm{~d}$, signifying retrograde transport $(H, M$, and $L$ are the heavy-, middle-, and low-molecular-weight neurofilament bands; $T$, tubulin bands).

similar proximal-to-distal translocation with time of labeled neurofilament and tubulin bands. The use of age-matched littermates all injected at $30 \mathrm{~d}$ old provided for accurate comparisons since the rate of axonal transport is related to age of the animal (Hoffman et al., 1985). At $36 \mathrm{~d}$ after labeling, the transport velocities (distance of peak from DRG/time) for both C57 and Ola mice were calculated as approximately $0.5 \mathrm{~mm} / \mathrm{d}$ for neurofilament and $0.75 \mathrm{~mm} / \mathrm{d}$ for tubulin. These values provide the most widely used estimate of the transport velocity. Better measures, such as the distance of the 50th percentile of radioactivity from the DRG, could not be used because of the broadness of the "peak" in relation to the length of the nerve (see below). However, these approximate rates are consistent with previous estimations for the velocity of slow transport in rodent peripheral nerves (Hoffman and Lasek, 1975; Lasek and Hoffman, 1976; Watson et al., 1989).

As noted in previous studies of slow transport (Ochs, 1975; Nixon and Logvinenko, 1986; Hollenbeck, 1989; Watson et al., 1989), the transport profiles of labeled slow component proteins showed a broad peak of activity with a "tail" of labeled proteins trailing behind the leading edge (Fig. 2). This tail represented a significant amount of the labeled neurofilament and tubulin proteins in the transport wave, and at early times after labeling $(<28 \mathrm{~d})$ it was mostly contained in the portion of nerve proximal to the ligation. Because we wanted to "capture" for analysis as much of the labeled cytoskeletal components as possible within the ligated distal stump, we chose our experimental time points in order to maximize the proportion of the slow component contained within the available portion of nerve distal to the site of ligation.

To determine if the transport of radiolabeled cytoskeletal proteins was altered by axotomy, the transport profile of each axotomized nerve was compared to those of the two littermate controls. One control nerve was removed at the time of ligation of the test animal, and the other was removed at the time the test animal was killed. A $14 \mathrm{~d}$ time interval between ligation and death was chosen because it allowed enough time to identify significant changes in the locations of labeled proteins travelling at $\approx 0.5 \mathrm{~mm} / \mathrm{d}$ and because $>85 \%$ of Ola sensory axons remain intact at $14 \mathrm{~d}$ after axotomy (Glass and Brushart, unpublished observations). The ligated test animal and the two control animals are subsequently referred to as an "experimental set" for each postinjection time point. This analysis allowed us to identify where labeled proteins were at the time of ligation and at the time of death in unligated nerves.

We tested three schemes for the timing of axotomy after labeling: ligation at $28 \mathrm{~d}$, death at $42 \mathrm{~d}$ (28/42 group); ligation at 35 days, death at $49 \mathrm{~d}(35 / 49$ group); ligation at $56 \mathrm{~d}$, death at $70 \mathrm{~d}$ (56/70 group). In each group there were duplicate threeanimal sets (Table 1).

\section{Visual analysis of gel fluorograms}

In four of the six experimental groups, 28/42 (1), 35/49 (2), 56/ 70 (1), when compared to the profile of the nonligated animal killed at the earlier time point, the transport profile of the ligated nerve showed a relative increase in intensity of the labeled neurofilament and tubulin bands in the two or three segments just distal to the ligation. An example of this is shown in Figure 3. Animals 1-3 were injected on the same day, and at $35 \mathrm{~d}$ animal 1 was killed and animal 3 underwent ligation of the labeled sciatic nerve $8 \mathrm{~mm}$ from the DRG. At day 49 , animals 2 and 3 were killed and the nerves from all three animals were analyzed. In animal 3, there was an accumulation of labeled neurofilament and tubulin in the segments just distal to the ligation compared to the corresponding segments in animal 1 . We assume that the labeled "waves" of cytoskeletal bands in both 

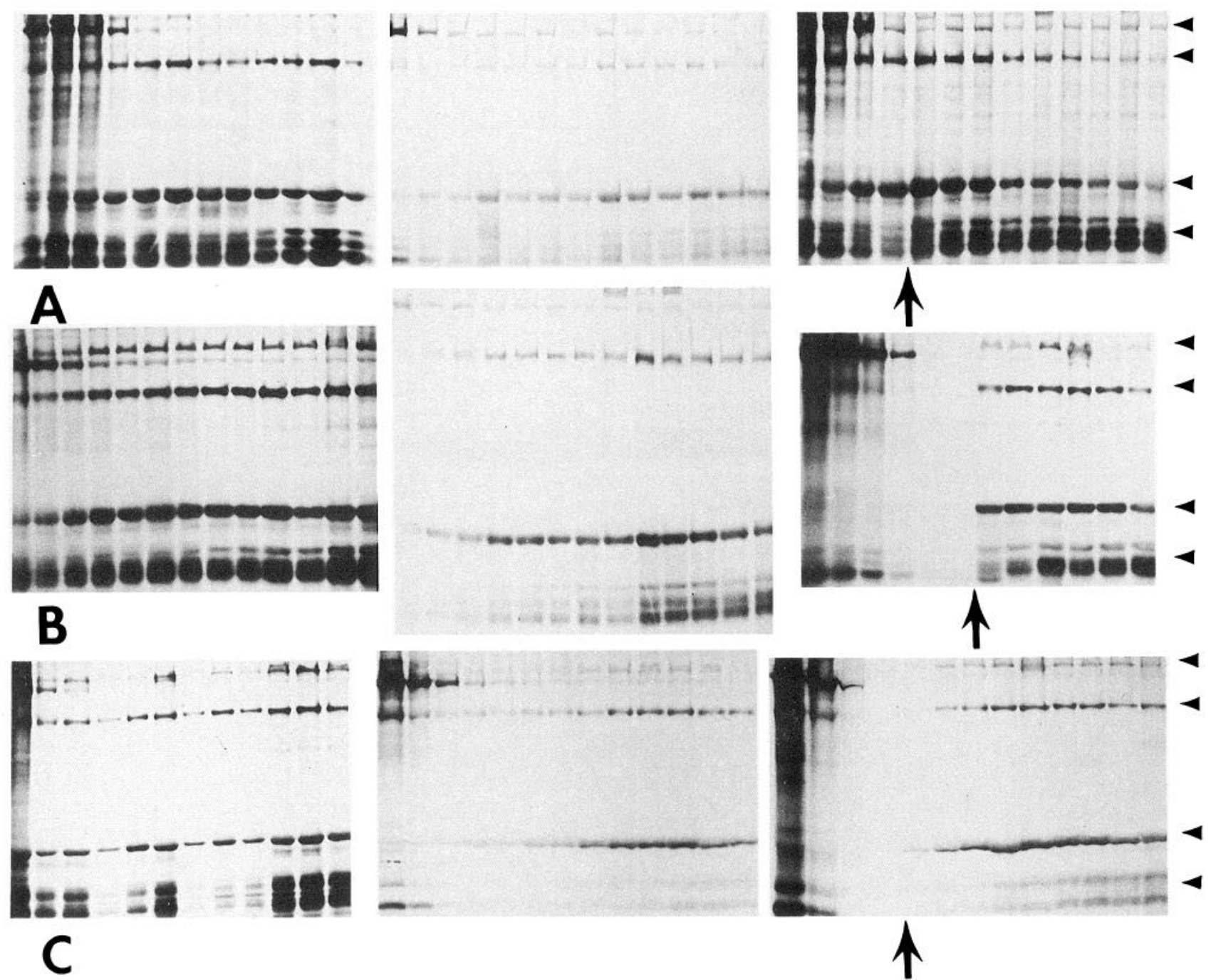

Figure 4. Gel fluorograms from experimental groups 28/35 (A), 35/49 (B), and 56/70 (C). As in Figure 3, the first fluorogram in each group is from the animal killed at the initial experimental time point, the middle fluorogram is from the animal killed $14 \mathrm{~d}$ later, and the third fluorogram is from the animal ligated at the initial time point and killed $14 \mathrm{~d}$ later. Sequential $2 \mathrm{~mm}$ segments from the DRG distally are represented left to right in each gel; the arrow points to the site of ligation. The arrowheads at the right of each group depict the bands representing (from bottom to top, respectively) tubulins, NF-L, NF-M, and NF-H. As in Figure 3, these gels demonstrate the proximal-to-distal progression of the labeled bands and the redistribution of label to more proximal segments after ligation. At the late time points $(C, 56$ and $70 \mathrm{~d})$, a significant proportion of the tubulin radioactivity has moved past the most distal segment, making interpretation of relative distributions difficult (see Discussion).

nerves were at similar distances from the DRG at day 35 . As demonstrated in the gel fluorogram for animal 1, the peaks for these transport profiles were at about $16 \mathrm{~mm}$ for neurofilament and $\geq 24 \mathrm{~mm}$ for tubulin. The fluorogram of the sciatic nerve from animal 3, a nerve that survived while disconnected from its cell bodies for an additional $14 \mathrm{~d}$, showed the transport peak for neurofilament at $10-12 \mathrm{~mm}$ and for tubulin at $16-18 \mathrm{~mm}$ from the DRG. The gel fluorograms representing the other animal groups are shown in Figure 4. This relative shift in radioactivity for cytoskeletal bands toward more proximal segments provides evidence for retrograde transport of these proteins.

\section{Quantitative analysis of gel fluorograms}

The laser densitometric data corroborated the visual interpretation of the fluorograms and permitted quantitative analysis of the distribution of radioactive bands. The relative intensities and distributions of the bands corresponding to the low-, mid- dle-, and high-molecular-weight neurofilament peptides were the same, as were those for $\alpha$ - and $\beta$-tubulins. Therefore, the data were summed and analyzed as total labeled neurofilament and tubulin proteins. Figure 5 demonstrates graphically the quantitative data from the gels from animals 1-3 (shown in Fig. 3 ). The counts from the first $4 \mathrm{~mm}$ of nerve (segments 1 and 2) were excluded so that the radioactivity due to nonspecific radioactive contamination of the tissue at the time of injection was removed from the analysis. As expected, there was progression distally of the peaks of radioactivity for neurofilament and tubulin between days 35 and 49 , with transport rates as described above, shifting the peak distally beyond the last segment at $49 \mathrm{~d}$.

Comparison of the data from animal 3 with that from the littermate controls showed a relative increase in the percentage of radioactivity associated with the neurofilament and tubulin bands in the segments just distal to the ligation. The peak of 
radioactivity for these bands was shifted proximally, about 4$6 \mathrm{~mm}$ over the $14 \mathrm{~d}$ interval.

These data were also expressed as the percentage of radicactivity in the two segments $(4 \mathrm{~mm})$ just distal to the ligation compared with that in the remainder of the distal stump (Fig. 1). For the example illustrated above (animals 1-3 illustrated in Fig. 5), the percentage of radioactivity in the neurofilament and tubulin bands, respectively, was $18 \%$ and $12 \%$ at $35 \mathrm{~d}, 17 \%$ and $10 \%$ at $49 \mathrm{~d}$, and $30 \%$ and $20 \%$ at $49 \mathrm{~d}$ when ligated at 35 d. This type of analysis suggested a shift proximally of radioactivity in the ligated nerves for neurofilament proteins in one of two sets in groups $28 / 42$ and 56/70, and for both groups $35 /$ 49 (fluorograms shown in Fig. 4). A proximal shift of tubulin bands was suggested in one of two sets in group (35/42), but was not unequivocally shown by quantitative means in the other groups because of difficulties in "capturing" tubulin proteins within the experimental windows (see below).

\section{Discussion}

These results demonstrated that there was a slow, bidirectional redistribution of radiolabeled neurofilament and tubulin proteins in surviving transected axons of the $\mathrm{C} 57 \mathrm{BL} / \mathrm{Ola}$ mouse. There was a shift proximally (toward the cell body) of a portion of the transport wave during the $14 \mathrm{~d}$ between nerve ligation and death, in accord with a distal to proximal (retrograde) transport of neurofilament and tubulin proteins. These data are consistent with the previous studies from our laboratory that showed similar patterns of cytoskeletal redistribution in transected Ola nerves by morphological and immunochemical techniques (Glass and Griffin, 1991; Watson et al., 1993). Morphologically, transected axons showed gradual dissociation and redistribution of the cytoskeleton, which resulted in massive accumulations of neurofilaments at both proximal and distal cut-ends of the axon (Glass and Griffin, 1991). Doubly transected Ola nerves were subjected to regional analysis by ELISA for neurofilament and tubulin content by cutting them into sequential $1 \mathrm{~mm}$ segments. At about $14 \mathrm{~d}$ after transection, the segments at either end of the nerve showed a gradual accretion of neurofilament and tubulin proteins, while those toward the center showed a reduction in their content of cytoskeletal proteins (Watson et al., 1993). These three methods for demonstrating the distribution of cytoskeletal proteins in axons showed mutually consistent results that, taken together, provide strong evidence that movement of cytoskeletal proteins occurs bidirectionally in these transected nerves.

The most informative data supporting our conclusion comes from the animals ligated at $35 \mathrm{~d}$ and killed at $49 \mathrm{~d}$ (group 35/ 49 ). Both visually and quantitatively these transport gels showed a relative shift of labeled neurofilament and tubulin bands back toward the cell body in ligated nerves. The demonstration of retrograde transport in the $28 / 42$ and $56 / 70$ groups was not as clear as in the $35 / 49$ groups because the "window" for catching the majority of the transport wave in the portion of the nerve analyzed was either taken too soon or too late after labeling. This problem arises because the transport peak is broad relative to the length of sciatic nerve available for analysis. For example, in the $28 / 42$ group, even though the leading edge of transport was within the analyzed portion, a significant amount was caught proximal to the site of ligation and was thus "lost" when the distal stump was analyzed. Similarly, the longer time points probably allowed too much of the radioactivity to "leave" the analyzed segment before ligation. This issue was more of a prob-

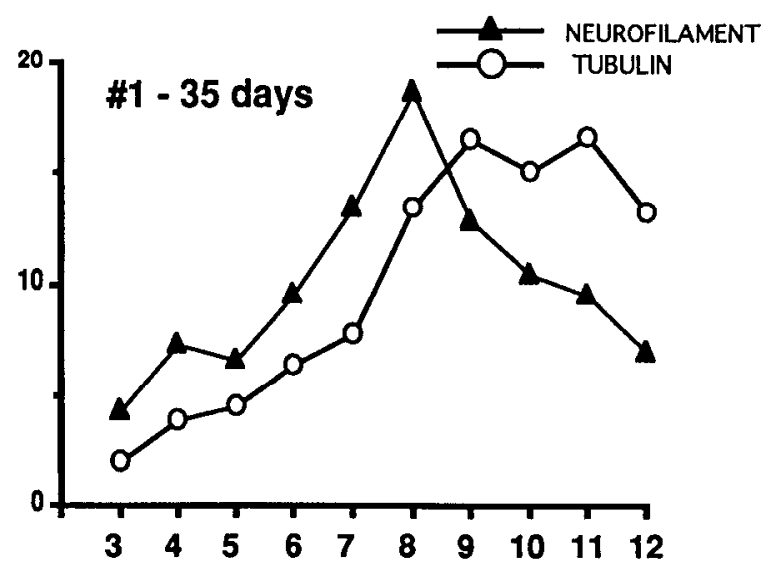

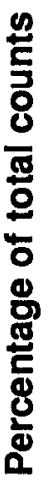
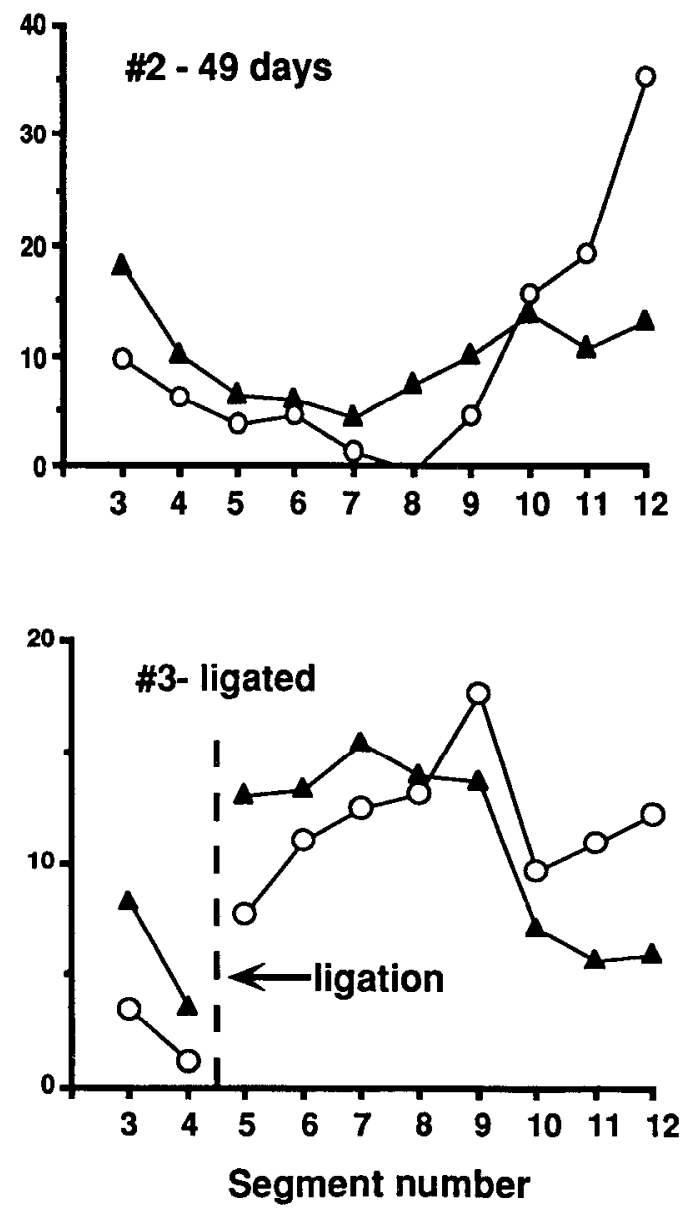

Figure 5. Quantitative laser densitometric data from the gel fluorograms shown in Figure 3. The percentage of total counts in each segment is graphed versus the segment number; segments 1 and 2 were excluded so that the intensity of bands in these segments due to local radioactive contamination around the DRG did not skew the results (see Fig. 1). Each point represents the percentage from the homogenate of a $2 \mathrm{~mm}$ segment of nerve taken sequentially from the DRG distally. The transport peaks at $35 \mathrm{~d}$ and $49 \mathrm{~d}$ (animals \#I and \#2) are demonstrated; for neurofilament approximately $16 \mathrm{~mm}$ and $22 \mathrm{~mm}$, for tubulin approximately 22 and $>24 \mathrm{~mm}$ at 35 and $49 \mathrm{~d}$, respectively. The data from animal \#3 (ligated at $35 \mathrm{~d}$ and killed at $49 \mathrm{~d}$ ) shows a proximal shift of the transport peaks, with accumulation of radioactivity in the segments just distal to the ligation. 
lem for the analysis of tubulin proteins since a significant portion of these proteins travel in the faster $\mathrm{SCb}$ wave (Lasek and Hoffman, 1976). In addition, in the longer lasting experiments the ${ }^{35} \mathrm{~S}$ label $\left(t_{1 / 2}=80 \mathrm{~d}\right)$ had decayed substantially. Even with these technical problems, the profiles of two of out of four animals in these groups had consistent retrograde movement of neurofilament proteins.

\section{Comparison to previous studies of slow transport}

Because of the rapid course of Wallerian degeneration, comparable experiments have not previously been possible in mammals. In nonmammalian systems in which axons degenerate at slower rates analysis of cytoskeletal redistribution in transected nerves have not suggested a retrograde component of transport. In the garfish olfactory nerve the axonal constituents "cleared out" from proximal to distal at the rate of slow transport (Cancalon, 1983). In the goldfish optic nerve slow transport was demonstrated to continue from proximal to distal for at least $24 \mathrm{hr}$ after separation from the cell bodies (Alpert et al., 1980).

The original demonstration of slow transport of neurofilaments and tubulin by the pulse-labeling method was performed in the rat (Willard et al., 1974; Hoffman and Lasek, 1975). These studies showed two or three transport peaks moving from proximal to distal at $1.0-1.2 \mathrm{~mm} / \mathrm{d}$. The transport profiles were followed to $135 \mathrm{~d}$ after labeling and were interpreted as showing only progressive anterograde movement of the labeled proteins. Subsequent reports of slow axonal transport showed similar profiles demonstrating proximal to distal movement of cytoskeletal proteins (Ochs and Johnson, 1969; Griffin et al., 1978, 1982, 1984; Lasek et al., 1992). These pulse-labeling experiments did not, however, preclude the existence of a retrograde slow component. Two common features of slow transport profiles are (1) the progressive widening of the transport wave as it moves from proximal to distal and (2) the tail of labeled cytoskeletal proteins that trail behind the major peaks of transport. These features of the transport wave suggest that the cytoskeleton does not necessarily move as a compact unit. Although this issue is vigorously debated, it is possible that these characteristics of slow transport profiles represent deposition of cytoskeletal elements along the axon, perhaps for replenishment of a predominantly stationary cytoskeleton (Nixon and Logvinenko, 1986; Ochs et al., 1989). In addition, it is unclear what proportion of cytoskeletal protein the moving wave actually represents, and it may constitute only a minor amount of total axonal cytoskeleton. This has recently been demonstrated for tubulin proteins in regenerating motor axons (Hoffman et al., 1992). The present results suggest another possible explanation for the broadening peaks and trailing tail: they may represent a proportion of labeled protein that is moving distal to proximal. The transport wave would then represent the net movement of labeled proteins that are moving both anterograde and retrograde. This model would not only explain the broadening peak and tail, but could explain why the relative amount of radioactivity in the transport peak becomes smaller as the wave moves down the nerve (see Fig. 1 in Hoffman and Lasek, 1975). Of course, a retrograde component of cytoskeletal transport may represent a phenomenon that only occurs in pathological situations (i.e., in transected nerves), or may be a unique characteristic of this mutant strain. A model of delayed degeneration in nerves from normal mammals is necessary to detect whether retrograde cytoskeletal transport is restricted to Ola.

In recent years there has been a reevaluation of the nature of slow transport (Hollenbeck, 1989), which has called into question whether the cytoskeleton is translocated as "bulk flow" as originally hypothesized. In several experimental systems, including the rat optic nerve (Nixon and Logvinenko, 1986), and mouse DRG neurons (Okabe and Hirokawa, 1990; Okabe et al., 1993), there is evidence that at least a large proportion of both microtubules and neurofilaments in adult, nongrowing axons are maintained as a stationary network. This stationary cytoskeleton could be resupplied continuously by polypeptide subunits transported from the perikaryon to areas of cytoskeletal turnover (Ochs, 1982). Pulse-labeling analysis of axonal transport defines only newly synthesized protein and cannot elucidate what proportion of total cytoskeletal protein these labeled populations represent. It may be, as has been shown for tubulin proteins (Hoffman et al., 1992), that the pulse-labeled wave of neurofilaments moving within the axon is only a minor amount of total neurofilament protein (Nixon and Logvincnko, 1986; Okabe et al., 1993). This moving wave may be important for replenishing axonal constituents that are turning over, and may represent a minor nonpolymerized component of the axonal cytoskeleton.

As new data emerges, the nature and function of slow axonal transport have proved more complex than originally viewed. As shown here, the Ola mouse provides an experimental system that yields a new perspective on axonal transport systems. These mature axons, maintained in vivo or in organ culture, can be manipulated and observed over relatively long periods of time in order to test hypotheses regarding slow transport and the economy of the axonal cytoskeleton.

\section{References}

Alpert RM, Grafstein B, Edwards DL (1980) Slow axonal transport in goldfish optic axons. Soc Neurosci Abstr 6:83.

Baruah JK, Rasool CG, Bradley WG, Munsat TL (1981) Retrograde axonal transport of lead in rat sciatic nerve. Neurology 31:612-616.

Bisby MA (1976) Orthograde and retrograde axonal transport of labeled protein in motoneurons. Exp Neurol 50:628-640.

Brimijoin S, Wiermaa MJ (1977) Rapid axonal transport of tyrosine hydroxylase in rabbit sciatic nerve. Brain Res 120:77-96.

Cancalon P (1983) Proximodistal degeneration of C-fibers detached from their perikarya. J Cell Biol 97:6-14.

Gainer H, Fink DJ (1982) Evidence for slow retrograde transport of serum albumin in rat sciatic nerve. Brain Res 233:404-408.

Glass JD, Griffin JW (1991) Neurofilament redistribution in transected nerves: evidence for bidirectional transport of neurofilaments. J Neurosci 11:3146-3154.

Griffin JW, Price DL, Drachman DB, Engel WK (1976) Axonal transport to and from the motor nerve ending. Ann NY Acad Sci 274:3145.

Griffin JW, Price DL, Engel WK, Drachman DB (1977) The pathogenesis of reactive axonal swellings: role of axonal transport. J Neuropathol Exp Neurol 36:214-227.

Griffin JW, Hoffman PN, Clark AW, Carroll PT, Price DL (1978) Slow axonal transport of neurofilament proteins: impairment by 3,3'-iminodipropionitrile administration. Science 202:633-635.

Griffin JW, Hoffman PN, Price DL (1982) Axonal transport in beta, beta'-iminodipropionitrile neuropathy. In: Axoplasmic transport in physiology and pathology (Weiss DG, Gorio A, eds), pp 109118. Berlin: Springer.

Griffin JW, Anthony DC, Fahnestock KE, Hoffman PN, Graham DG (1984) 3,4-Dimethyl-2,5-hexanedione impairs the axonal transport of neurofilament proteins. J Neurosci 4:1516-1526.

Hoffman PN, Lasek RJ (1975) The slow component of axonal transport: identification of major structural polypeptides of the axon and their generality among mammalian neurons. J Cell Biol 66:351-366.

Hoffman PN, Griffin JW, Gold BG, Price DL (1985) Slowing of neurofilament transport and the radial growth of developing nerve fibers. J Neurosci 5:2920-2929. 
Hoffman PN, Lopata MA, Watson DF, Luduena RF (1992) Axonal transport of class II and III beta-tubulin: evidence that the slow component wave represents the movement of only a small fraction of the tubulin in mature motor axons. J Cell Biol 119:595-604.

Hollenbeck PJ (1989) The transport and assembly of the axonal cytoskclcton. J Ccll Biol 108:223-227.

Kristensson K, Sjostrand J (1972) Retrograde transport of protein tracer in the rabbit hypoglossal nerve during regeneration. Brain Res 45:175-181.

Lasek RJ, Hoffman PN (1976) The neuronal cytoskeleton, axonal transport and axonal growth. In: Cell motility, Book C, Microtubules and related proteins (Goldman R, Pollard T, Rosenbaum J, eds), pp 1021-1051. Cold Spring Harbor, NY: Cold Spring Harbor Laboratory.

Lasek RJ, Paggi P, Katz MJ (1992) Slow axonal transport mechanisms move neurofilaments relentlessly in mouse optic axons. J Cell Biol 117:607-615.

LaVail JH, LaVail MM (1974) The retrograde intraaxonal transport of horseradish peroxidase in the chick visual systems: a light and microscopic study. J Comp Ncurol 157:303-358.

Lunn ER, Perry VH, Brown MC, Rosen H, Gordon S (1989) Absence of Wallerian degeneration does not hinder regeneration in peripheral nerve. Eur J Neurosci 1:27-33.

Nixon RA, Logvinenko KB (1986) Multiple fates of newly synthesized neurofilament proteins: evidence for a stationary neurofilament network distributed nonuniformly along axons of retinal ganglion cell neurons. J Cell Biol 102:647-659.

Ochs S (1975) Retention and redistribution of proteins in mammalian nerve fibres by axoplasmic transport. J Physiol (Lond) 253:459-475.
Ochs S (1982) Axoplasmic transport and its relation to other nerve functions. New York: Wiley.

Ochs S, Johnson J (1969) Fast and slow phases of axoplasmic flow in ventral root nerve fibres. J Neurochem 16:845-853.

Ochs S, Jersild A Jr, Li J-M (1989) Slow transport of freely movable cytoskeletal components shown by bcading partition of nerve fibers in the cat. Neuroscience 33:421-430.

Okabe S, Hirokawa N (1990) Turnover of fluorescently labelled tubulin and actin in the axon. Nature 343:479-482.

Okabe S, Miyasaka H, Hirokawa N (1993) Dynamics of the neuronal intermediate filaments. J Cell Biol 121:375-386.

Price DL, Griffin JW, Young A, Peck K, Stocks A (1975) Tetanus toxin: direct evidence for retrograde intraaxonal transport. Science 188:945-947.

Vallee RB, Bloom GS (1991) Mechanisms of fast and slow axonal transport. Annu Rev Neurosci 14:59-92.

Watson DF, Glass JD, Griffin JW (1993) Redistribution of cytoskeletal proteins in mammalian axons disconnected from their cell bodies. $\mathbf{J}$ Neurosci 13:4354-4360.

Watson DW, Hoffman PN, Fittro KP, Griffin JW (1989) Neurofilament and tubulin transport slow along the course of mature motor axons. Brain Res 477:225-232.

Willard M, Cowan WM, Vagelos PR (1974) The polypeptide composition of intraaxonally transported proteins: evidence for four transport velocities. Proc Natl Acad Sci USA 71:2183-2187.

Zelena J, Lubinska L, Gutmann E (1968) Accumulation of organelles at the ends of interrupted axons. Z Zellforsch Mikrosk Anat 91:200219 